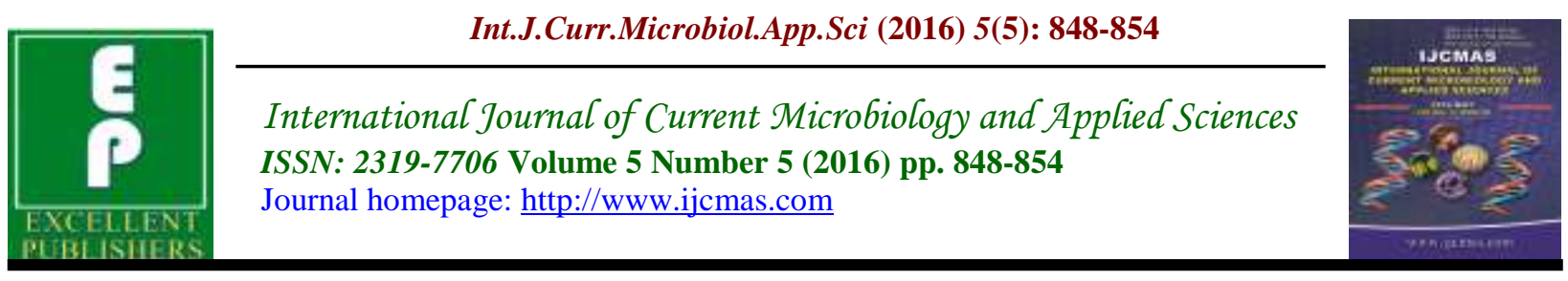

Original Research Article

http://dx.doi.org/10.20546/ijcmas.2016.505.087

\title{
Isolation of Group B Streptococci from Antenatal Women
}

\author{
Tupili Ramya, Usham Gangaram* and K.H. Vasudeva Naidu
}

Department of Microbiology, Sri Vekateshwara Medical College, Tirupathi, India

*Corresponding author

\begin{tabular}{|c|c|}
\hline \multirow{6}{*}{$\begin{array}{l}\text { Ke y w o r d s } \\
\text { Group B } \\
\text { streptococcus, } \\
\text { Colonization, } \\
\text { Drug resistance, } \\
\text { Drug sensitivity. }\end{array}$} & A B S T R A C T \\
\hline & \multirow{9}{*}{$\begin{array}{l}\text { Prevalence of Group-B streptococcal (GBS) infection varies from place to place } \\
\text { and this organism is responsible for serious infections in newborns such as } \\
\text { septicemia and meningitis. The present study was carried out to find out the } \\
\text { prevalence \& antibiotic sensitivity of GBS in primigravida \& to identify the risk } \\
\text { factors. } 300 \text { pregnant women were studied attending the antenatal clinics in } \\
\text { Government Maternity Hospital, Tirupati. Two vaginal swabs were taken from } \\
\text { each pregnant women. The two swabs were immediately transported to the } \\
\text { laboratory for processing. Direct Gram stain was done from one swab and the other } \\
\text { swab was inoculated onto sheep blood agar plate and incubated at } 37^{\circ} \mathrm{C} \text { for } 24-48 \\
\text { hours. Identification was done based on Gram staining, colony morphology, } \\
\text { catalase reaction, CAMP test and Hippurate hydrolysis test } \& \text { Bacitracin resistance. } \\
\text { Of the } 300 \text { pregnant women screened, } 7 \% \text { were colonized by GBS. GBS } \\
\text { colonization rate was higher among pregnant women in third trimester who were < } \\
25 \text { years of age. All the isolates were sensitive to Penicillin, Ampicillin, } \\
\text { ceftriaxone, levofloxacin and vancomycin. GBS colonization rate among pregnant } \\
\text { women in third trimester of pregnancy is low in this area. Revised guidelines from } \\
\text { the Centers of Disease Control and Prevention (CDC), } 2010 \text { for the prevention of } \\
\text { perinatal GBS disease recommends that all pregnant women be screened for GBS } \\
\text { carriage between } 35 \text { and } 37 \text { weeks of gestation and intrapartum antibiotic } \\
\text { prophylaxis be given to colonized women at the time of labour onset or rupture of } \\
\text { membranes. }\end{array}$} \\
\hline & \\
\hline & \\
\hline & \\
\hline & \\
\hline & \\
\hline Artic & \\
\hline & \\
\hline & \\
\hline
\end{tabular}

\section{Introduction}

Group-B streptococci or Streptococcus agalactiae, is a well recognized pathogen in veterinary medicine because of its role as causative agent of bovine mastitis. There has been increasing interest in Group-B streptococci (GBS) due to their association with and recognition as pathogens of neonatal infections like sepsis and meningitis (Hood, et al., 1961; Eickhoff, et al., 1964).
They are present in $15-20 \%$ of pregnant women, in lower genital tract (HoogkampKorstanje, et al., 1982). Vaginal colonization by GBS during pregnancy is associated with life threatening neonatal infections acquired during passage through the birth canal, and it has been the most frequent cause of purulent meningitis in infants aged less than 2 months (Baker, et al., 1973; Barton, et al., 1973). 
Group-B streptococci has been associated with low-birth weight, premature delivery, preterm premature rupture of membranes, still birth and neonatal death suggesting that it has a marked predilection for pregnant women, fetus and neonates (Wheelver, 1966). The mother's birth canal is the principle reservoir of this infectious agent for infants who develop the more severe syndrome with early onset (Franciosi, et al ., 1973).

In India very few studies have been carried out, mainly to study the prevalence of GBS infections. The GBS colonization rate in the vaginal flora of pregnant women varied from 0.47 to $23.3 \%$ as reported by various workers (Arora, et al., 1994; Kishore, et al., 1986; Lakshmi, et al., 1998; Prakash, et al., 1976; Santosh Damyanti, et al., 1984; Uma Chaudhary, et al., 1981).

The factors controlling maternal GBS colonization and neonatal disease due to GBS are - age, number of previous pregnancies, phase of menstrual cycle, sexual activity, use of oral contraceptives (Baker, et al., 1977; Schauf, et al., 1976).

This study was undertaken in order to understand the magnitude of this problem in pregnant women in our area. The main aim of this study includes, to study the prevalence of group B Streptococcal infection from antenatal primi gravida attending antenatal clinic of government maternity Hospital attached to S.V. Medical college. And also to study drug sensitivity of group B streptococci to penicillin, ampicillin, ceftriaxone, Clindamycin, vancomycin.

\section{Material and Methods}

\section{Study Area and Period}

The present hospital based cross sectional study was carried out in the antenatal clinic \& Department of Microbiology, S.V. Medical College, Tirupati, from June 2012 to May 2013.

\section{Source Population}

300 pregnant women were studied attending the antenatal clinics in Government Maternity Hospital, Tirupati. These women were in the age group of 19 years to 37 years. The inclusion criteria for study were the presence of signs \& symptoms of pregnancy \& willingness to participate in the study. Detailed history of each case was taken during their clinical examination. Group B streptococcal positive women were divided in four groups: Group I: $\leq 20$ years; Group II: 21 to 25 years ; Group III: 26to30 years and Group IV: above30years.

\section{Data Collection, Processing and Analysis}

Two low vaginal swabs were taken aseptically prior to first pelvic examination. The swabs were immediately transported to the Microbiology laboratory. One swab was used for direct gram staining and the other swab was inoculated on to sheep blood agar containing 5\% sheep blood; it was incubated at $37^{\circ} \mathrm{C}$ for $24-48$ hours. Identification was done based on gram stain, colony morphology, catalase reaction, CAMP test, hippurate hydrolysis test.

\section{The Presumptive Diagnosis of GBS was based on the following Criteria}

Direct gram staining showing gram positive cocci arranged in pairs and short chains.

The colony appearance of GBS on sheep blood agar at 24 hours is usually grey, smooth, shiny, convex, moist, regular, soft and mucoid in appearance and about $1 \mathrm{~mm}$ in diameter, often surrounded by a small hazy zone of beta hemolysis. The confirmation of GBS was made by 
subculturing colony from the blood agar on to chocolate agar to check the catalase activity. A clean (grease free) glass slide was taken, 1 or 2 drops of $\mathrm{H}_{2} \mathrm{O}_{2}(3 \%)$ was put on the slide. Using a clean glass rod, a colony was picked and dipped into $\mathrm{H}_{2} \mathrm{O}_{2}$. Staphylococci produce catalase while streptotococi does not. Effervescence is seen in positive catalase test whereas no effervescence is seen in negative catalase test. Other confirmatory tests carried out were CAMP and Hippurate hydrolysis test.

Antimicrobial sensitivity of the GBS was done by the Kirby-Bauer disc diffusion method Fresh sub-cultures of GBS were used after overnight growth (16 hours) on blood agar plate.

The inoculum was prepared by suspending several of the colonies in sterile phosphate buffered saline ( $\mathrm{pH}$ 7.2) to achieve a turbidity of 0.5 McFarland standard. This resulted in a suspension containing approximately1-2 × $10^{8} \mathrm{CFU} / \mathrm{ml}$. A sterile cotton swab was dipped into the bacterial suspension, elevated above the liquid and rotated several times against the inside wall of the tube to remove excess of the inoculum.

This swab was streaked evenly in three different directions onto the blood agar containing 5\% sheep blood. Five antibiotic discs were employed namely Penicillin Penicillin (10 $\mu \mathrm{g} / \mathrm{disc})$, Ampicillin $(10 \mu \mathrm{g} /$ disc), Clindamycin ( $2 \mu \mathrm{g} /$ disc $)$, Ceftriaxone (30 $\mu \mathrm{g} /$ disc), Vancomycin $(30 \mu \mathrm{g} /$ disc. The data was analyzed and interpreted.

\section{Results and Discussion}

In the present study, out of 300 women, 21 (7\%) showed GBS colonization (figure 1). According to Table 1, most of the isolates were from the age group $\leq 20$ years $(8.73 \%)$, followed by age group 21 to 25 (7.18\%). By applying chi square test relationship between GBS colonization and age group was not statistically significant.

As per the Table 2, most of the GBS isolated from the third trimester of pregnancy (10.19\%). Out of 10 samples from the third trimester of pregnancy, one sample turned to be positive. This indicates that third trimester of pregnancy is a risk factor for the colonization of GBS, compared to the other trimester.

All the group-B streptococci showed 100\% sensitivite to Ampicillin, Penicillin, Ceftriaxone, Vancomycin and $90.47 \%$ sensitivity to Clindamycin.

A total of 300 primigravida women who were attending to antenatal clinic included in this study. These included females in the age group of 19 years to 37 years. Figure 1: Shows the prevalence of GBS is $7.0 \%$ in the present study.

Motlova, et al., (2004) showed that $29.3 \%$ of pregnant women were colonized by GBS. In a study done by Kavitha P Konikkara, et al., (2008) showed the GBS carriage rate $12 \%$. In comparison to the above studies, our study shows the incidence rate of $7.0 \%$, which is lower.

But when compared to the studies done by AA Kulkarni, et al., (2001) and Vijayan Sharmila, et al., (2011), which shows the colonization rate of $2.52 \%$ and $2.3 \%$ respectively. Our incidence rate was found to be higher.

The incidence rate in our study (7\%) correlates with the study done by Annie Rajaratnam, et al., (2013), which also showed the colonization rate of $8.3 \%$. And also correlates with study done by Vinay 
Hazare, et al., (2012), which showed the colonization rate of $7.5 \%$.

The reasons for varying results may be attributed to the fact that GBS maternal colonization varies from place to place. Other factors that may have contributed to this variation include socioeconomic factors, variation in clinical practices of samples collected and the technique used for sampling. Ethnic and genetic factors might play a role in variation of the rates of infection with GBS.

According to Table 1, in the present study most of the isolated strains were from cases belonging to age group less than and equals to 20 years $(8.73 \%)$ followed by the age group of $21-25$ years $(7.18 \%)$, thus in the present study, most of the GBS colonized pregnant women were from teenage and younger age group.

These findings are in correlation with that of Vinay Hazare, et al., (2012), Tsering Chomu Dechen, et al., (2010), the reasons for the predisposition of women younger than 21 years of age to vaginal colonization with GBS is less apparent. This relationship could be the result of age related development of local or humoral immunological responses that interfere with mucosal attachment and/ or persistence of GBS.

Table-2: Shows most of the GBS isolated from the third trimester of pregnancy $(10.19 \%)$. This indicates third trimester of pregnancy is a risk factor for the colonization of GBS, compared to the other trimester. According to Fatemi, et al., (2008), 7 (8.8\%) of 80 women with any kind of antibiotic therapy during third trimester and $61(24.4 \%)$ of 250 in those who were not receiving antibiotic, the results of culture were positive. Baker, et al., (1977) found that the colonization rate almost doubles between the second trimester and delivery.

According to Fashina, et al., (2008), Out of 100 women tested, 90 were positive in third trimester and 10 were in the second trimester and cultures were negative in the first trimester. In contrast, Hansen, et al., (2004) did not find any significant variation in the prevalence of GBS during pregnancy.

Revised guidelines from the Centers of Disease Control and Prevention (CDC), 2010 for the prevention of perinatal GBS disease recommends that all pregnant women be screened for GBS carriage between 35 and 37 weeks of gestation and intrapartum antibiotic prophylaxis be given to colonized women at the time of labour onset or rupture of membranes.

Figure-2: shows antibiotic sensitivity of 21 GBS isolates from mothers. All the strains were $100 \%$ sensitive to Ampicillin, Penicillin, Ceftriaxone, Vancomycin and $90.47 \%$ sensitive to Clindamycin.

Arora, et al., (1994) reported that all the 60 GBS were susceptible to Penicillin, Ampicillin, \& Erythromycin. Vinay Hazare, et al., (2012) showed that all the15 strains were $100 \%$ sensitive to ampicillin, erythromycin and penicillin followed by chloramphenicol (66.6\%). A marked resistance was observed with Gentamicin (100\%) and Kanamycin (80\%). 
Table.1 Isolation of GBS in Different Age groups

\begin{tabular}{|l|l|l|l|}
\hline Age group & $\begin{array}{l}\text { No. of } \\
\text { primigravida }\end{array}$ & $\begin{array}{l}\text { GBS } \\
\text { positive }\end{array}$ & $\begin{array}{l}\text { P } \\
\text { ercent }\end{array}$ \\
\hline$\leq 20$ years & 103 & 9 & 8.73 \\
\hline $21-25$ & 167 & 12 & 7.18 \\
\hline $26-30$ years & 23 & 0 & 0.0 \\
\hline$>30$ & 7 & 0 & 0.0 \\
\hline Total & $\mathbf{3 0 0}$ & $\mathbf{2 1}$ & $\mathbf{7 . 0}$ \\
\hline$\chi^{2}=0.927$ & $\mathrm{p}=0.818$ & Insignificant
\end{tabular}

Table.2 Isolation of GBS in different trimesters

\begin{tabular}{|l|l|l|l|}
\hline trimester & $\begin{array}{l}\text { No. of } \\
\text { primigravida }\end{array}$ & $\begin{array}{l}\text { GBS } \\
\text { Positives }\end{array}$ & Percent \\
\hline First & 34 & 0 & 0.0 \\
\hline Second & 60 & 0 & 0.0 \\
\hline Third & 206 & 21 & 10.19 \\
\hline Total & $\mathbf{3 0 0}$ & $\mathbf{2 1}$ & $\mathbf{7 . 0 0}$ \\
\hline$\chi^{2}=6.928 \quad \mathrm{p}=0.031$ significant
\end{tabular}

Fig.1 Prevalence of GBS in Primigravida

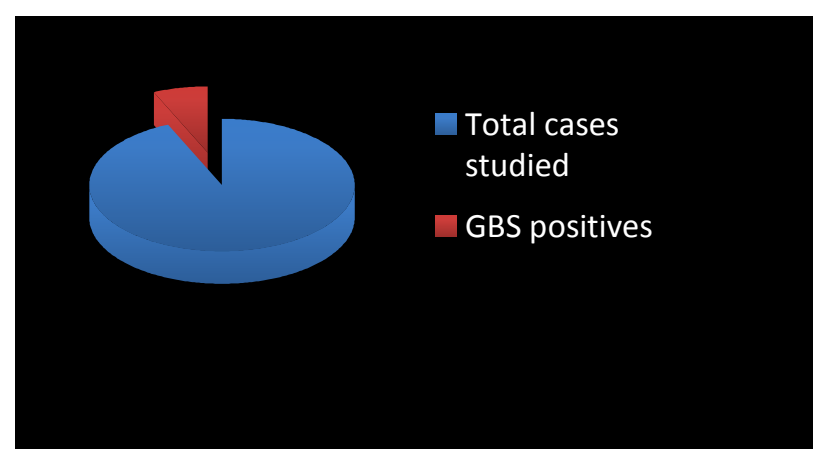

Fig.2 Antibiotic Sensitivity testing of 21 GBS isolates

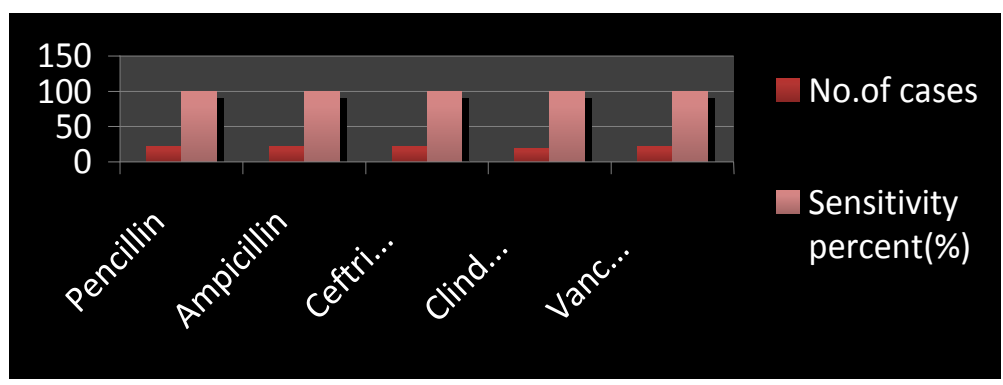

Fashina, et al.,(2008) reported,the sensitivity pattern of Streptococcus agalactiae showed that $100 \%$ were sensitive to Penicillin $\mathrm{G}$ and Erythromycin. Eighty percent $(80 \%)$ were sensitive to Ampicillin, Vancomycin and Augmentin, while Tetracycline was markedly resisted with a sensitivity of $30 \%$. 
According to Jannati, et al., (2012) all isolates were susceptible to ampicillin, vancomycin and penicillin. $96.7 \%$ and $93 \%$ of isolates were susceptible to erythromycin and clindamycin respectively and $83.9 \%$, $14.2 \%, 12.5 \%$ isolates were resistant to Cotrimoxazole ciprofloxacin and ceftriaxone respectively.

\section{Recommendation}

Most of the clinicians are not aware about the incidence of GBS in their area. So an attempt was made to find out the incidence of GBS in pregnant women which would help the clinicians to diagnose the GBS infections.

A low colonization rate of $7 \%$ was found among the pregnant women in third trimester of pregnancy in this part of study area. Among them higher colonization rate was found in pregnant women in third trimester of pregnancy who were $\leq 20$ years of age and primi gravidae. According to our study, risk factors for GBS colonization includes age less than 20 years and third trimester.

As per Revised guidelines from the CDC, 2010 for the prevention of perinatal GBS disease recommends that all pregnant women be screened for GBS carriage between 35 and 37 weeks of gestation and intrapartum antibiotic prophylaxis be given to colonized women at the time of labour onset or rupture of membranes".

\section{Acknowledgement}

Authors would like to express my deep sense of gratitude and thanks to staff of Department of Microbiology, S.V. Medical College, Tirupati for valuable guidance and help given throughout my paper work.

\section{References}

Hood, M., Jahney, A., Dameron, G. 1961. Beta hemolytic streptococcus group-B associated with problems of the perinatal period. Am. J. Obstet. Gynecol., 82(4): 809-818.

Eickhoff, T.C. et al. 1964. Neonatal sepsis and other infection due to group-B beta hemolytic streptococci. New Engl. J. Med., 271(24): 1223-1229.

Hoogkamp-Korstanje, J.A., Gerards, L.J., Cats, B.P. 1982. Maternal carriage and neonatal acquisition of Group-B streptococci. J. Infect. Dis., 145(6): 800-3.

Baker, C.J., Barrett, F.F., et al. 1973. Suppurative meningitis due to streptococci of Lancefield group-B. A study of 33 infants. J. Pediatr., 82(4): 724-729.

Barton, L.L,. Feigin, R.D., Lins, R. 1973. Group-B BHS meningitis in infants. $J$. Pediatr., 82(4): 719-723.

Wheelver, W.E. 1966. Non-epidemic infections peculiar to the gravid state. Am. J. Dis. Child., 112: 175.

Franciosi, R.A., et al. 1973. GBS neonatal and infant infections. J. Pediatr., 82(4): 707-718.

Arora, S., et al. 1994. Presumptive identification and antibiotic susceptibility of group-B streptococci. IJMR, 38: 185-190.

Kishore, K., et al. 1986. GBS colonization and neonatal outcome in north India. IJMR, 84: 492-494.

Lakshmi, V., et al. 1998. Incidence of group-B beta hemolytic streptococci in the vaginal flora of pregnant women. IJMR, 31(3): 240-244.

Prakash, et al. 1976. Group-B beta hemolytic streptococci and their serological types in human infections. IJMR, 64(7):1001-1007.

Santosh Damyanti, et al. 1984. Incidence of streptococcal infections (during $\mathrm{BOH}$, 
antenatal and puerperium). J. Obstet. Gynecol. India, 34: 513.

Uma Chaudhary, et al. 1981. Prevalence of GBS in obstetrical cases. IJMR, 73: 710-714.

Baker, C.J. et al. 1977. Vaginal colonization with group-B streptococcus: A study in college women. J. Infect. Dis., 135(3): 392-397.

Schauf, V., Hlaing, V. 1976. Group-B streptococcal colonization in pregnancy. Obstet. Gynecol., 47(6): 719-21.

Jannati, E., et al. 2012. Capsular serotype and antibiotic resistance of group $B$ streptococci isolated from pregnant women. Iranian J. Microbiol., Vol 4: 130-135.

Kulkarni, A.A., Pawar, S.G., Dharmadhikari, C.A., Kulkarni, R.D. 2001. Colonization of pregnant women and their new born infants with group-B streptococci. Indian J. Med. Microbiol., 19: 1-4.

Sharmila, V., Joseph, N.M., Arun Babu, T.A., Chaturvedula, L., Sistla, S. 2011. Genital tract group B Streptococcal colonization in pregnant women. $J$. Infect. Dev. Ctries., 5: 592-4.

Annie Rajaratnam, Thomas, S., Kuruvilla, Beena Antony. 2013. Prevalence of Group B Streptococci colonization among pregnant women in a tertiary care hospital in coastal Karnataka. Int. J. Appl. Biol. Pharma. Technol., 308.

Vinay Hajare, et al. 2012. Antibiogram of Group B streptococcl isolated from the vagina of pregnant women in third trimester of pregnancy. People $J$. Scientific Res., Vol.5(2).

Tsering Chomu Dechen, Kar Sumit, Pal Ranabir. 2010. Correlates of Vaginal Colonization with Group B Streptococci among Pregnant Women. Glob. Infect. Dis., 2(3): 236-241.

Farnaz Fatemi et al. 2009. Colonization rate of Group B Streptococci in pregnant women using GBS Agar Medium. Acta Medica Iranica, 47(1): 25-30.

Fashina, et al. 2010. Isolation and characterization of group B streptococci and other pathogens among pregnant women in Ibadan, Southwestern Nigeria. J. Appl. Biosci., 29: 1781-1792.

Jannati, E., et al. 2012. Capsular serotype and antibiotic resistance of group B streptococci isolated from pregnant women. Iranian J. Microbiol., Vol 4: 130-135.

Hansen, et al. 2004. Dynamics of Streptococcus agalactiae colonization in women during and after pregnancy and in their infants. J. Clin. Microbiol., 42: 83-89.

Motlová, J., Straková, L., Urbášková, P., Sak, P., Sever, T. 2004. Vaginal \& rectal carriage of Streptococcus agalactiaein the Czech Republic: incidence, serotypes distribution \& susceptibility to antibiotics. Indian $J$. Med. Res., 119: 84-7.

Konikkara, K.P., Baliga, S., Shenoy, S.M., Bharati, B. 2013. Comparison of various culture methods for isolation of Group B Streptococcus from intrapartum vaginal colonization. $J$. Lab Physicians, 5: 42-5.

\section{How to cite this article:}

Tupili Ramya, Usham Gangaram and Vasudeva Naidu, K.H. 2016. Isolation of Group B Streptococci from Antenatal Women. Int.J.Curr.Microbiol.App.Sci. 5(5): 848-854. doi: http://dx.doi.org/10.20546/ijcmas.2016.505.087 